\title{
Rapid detection of anti-hepatitis A virus neutralizing antibodies in a microplate enzyme immunoassay
}

\begin{abstract}
Correspondence
Ali Azizi

aazizi@uottawa.ca
\end{abstract}

Received 24 April 2009

Accepted 13 July 2009

\author{
Ali Azizi, ${ }^{1}{ }^{2,3}$ Danylo Sirskyj, ${ }^{1}$ Richard Weltzin, ${ }^{1}$ David E. Anderson ${ }^{1}$ \\ and Francisco Diaz-Mitoma ${ }^{1,2,3}$
}

\author{
${ }^{1}$ Variation Biotechnologies Inc., 1740 Woodroffe Avenue, Building 400, Ottawa, ON K2G 3R8, \\ Canada \\ ${ }^{2}$ Infectious Disease and Vaccine Research Center, Children's Hospital of Eastern Ontario Research \\ Institute, 401 Smyth, Ottawa, ON K1H 8L1, Canada \\ ${ }^{3}$ Department of Pathology and Laboratory Medicine, University of Ottawa, 451 Smyth, Ottawa, \\ ON K1H 8M5, Canada
}

\begin{abstract}
The slow growth of hepatitis A virus (HAV) in cell culture is one of the primary pitfalls in the development of sensitive and rapid methods for the detection and quantification of HAV and associated neutralizing antibodies. Currently, in vitro assays frequently require 8 days or more to detect and quantify the presence of HAV neutralizing antibodies. This study describes a rapid immunoassay that allowed the detection of anti-HAV neutralizing antibodies in only 3 days. This microplate-based enzymic assay may be applicable in virological diagnostics, in evaluating the immunogenicity of HAV vaccines and in quantifying neutralizing antibodies during the course of HAV infection.
\end{abstract}

\section{INTRODUCTION}

Hepatitis A virus (HAV), a member of the family Picornaviridae, is a non-enveloped, positive-sense RNA virus with a pervasive worldwide transmission (Brown, 1989). HAV causes acute liver infection with a sudden onset of symptoms such as fever and nausea (Jelic et al., 1990; Nainan et al., 2006). The virus is transmitted via the faecal-oral route and infects approximately 1.4 million people every year (Chen \& Cantrell, 2006). The HAV genome encodes a single polyprotein of approximately $200 \mathrm{kDa}$, which is subsequently processed into the structural proteins VP1-VP4 encoded by the viral region $\mathrm{P} 1$, and non-structural polypeptides encoded by viral regions P2 and P3 (Endo et al., 2007). HAV grows extremely slowly in cell culture and often replicates without any visible cytopathic effect, unlike other members of the family Picornaviridae such as poliovirus and human rhinovirus (Gauss-Muller et al., 1986; Stapleton et al., 1993; Zahn et al., 1984). Various in vitro assays have been developed to assess the activity of anti-HAV neutralizing antibodies; however, these assays are often lengthy (requiring 8 days-3 weeks) (Beales et al., 1996; Cao et al., 2008; Kim et al., 2004; Konduru et al., 2008) and may be more labour-intensive than microplate-based assays. Thus, a simpler and more rapid method for detecting and quantifying HAV neutralizing antibodies, perhaps amenable to a higher-throughput format, would be beneficial.

Abbreviation: FBS, fetal bovine serum.
Over the past few years, cytopathic variants of HAV have been generated (Brack et al., 1998; Emerson et al., 1993). These HAV strains cause acute rather than persistent infection and produce a much higher viral yield than noncytopathic variants. Using a cytopathic variant, we have developed a sensitive, specific and reproducible microplate-based assay for evaluating HAV neutralizing antibody responses. In this immunoassay, only one replication cycle of HAV appeared to be required in order to detect infectivity. To our knowledge, this is the first report that describes a colorimetric assay capable of detecting HAV infectivity and HAV neutralizing antibodies in only 3 days.

\section{METHODS}

Cells and virus. Fetal rhesus monkey kidney (FRhK-4) cells and HM175/18f, a cell-culture-adapted, cytopathic variant of the HM175 strain of HAV (Lemon et al., 1991), were obtained from Dr Syed Sattar (University of Ottawa, Canada). FRhK-4 cells were grown in Iscove's modified Dulbecco's medium (IMDM; Hyclone, Thermo Fisher Scientific) supplemented with $4 \mathrm{mM}$ L-glutamine, $0.4 \%$ HEPES, $10 \%$ heat-inactivated fetal bovine serum (FBS) (Hyclone, Thermo Fisher Scientific) and $1 \%$ penicillin/streptomycin (Cellgro) at $37{ }^{\circ} \mathrm{C}$ and $5 \% \mathrm{CO}_{2}$. The infection medium contained $2 \% \mathrm{FBS}$. Confluent cell monolayers were washed with PBS (Fisher) and trypsinized with $0.2 \%$ Trypsin/EDTA solution (Sigma). The HM175/ $18 \mathrm{f}$ virus strain was propagated in FRhK-4 cells and virus titre was quantified by plaque assay.

Serum samples. Serum samples from rhesus monkeys immunized with commercial HAV vaccine (Havrix 1440; GlaxoSmithKline) were 
collected approximately 2 weeks after the second of two vaccinations. Animal procedures were carried out at Frontier Biosciences (Chengdu, PR China). Human serum was collected from HAVvaccinated healthy individuals. All serum samples were heatinactivated for $30 \mathrm{~min}$ at $56{ }^{\circ} \mathrm{C}$ prior to use.

Neutralization assay. FRhK-4 cells were seeded in 96-well flatbottomed plates (Corning) at a density of $2.5 \times 10^{3}$ cells per well with IMDM supplemented with $10 \%$ FBS and $1 \%$ penicillin/streptomycin. The following day, the cells were washed with PBS and the medium was replaced with $100 \mu 12 \% \mathrm{FBS} / \mathrm{IMDM}$ and $1 \%$ penicillin/ streptomycin. Sera and control samples were serially diluted in $2 \%$ FBS/IMDM in a 96-well round-bottomed plate (Corning) in a $100 \mu \mathrm{l}$ final volume. Wells used as the virus control (virus alone) received $200 \mu \mathrm{l} \mathrm{HAV}$ diluted in $2 \% \mathrm{FBS} / \mathrm{IMDM}$. Wells used as the cell control (cells alone) received $20 \mu \mathrm{l} 2 \%$ FCS/IMDM. Diluted HAV $(100 \mu \mathrm{l}$; $1 \times 10^{6}$ p.f.u. $\mathrm{ml}^{-1}$ ) was then added to all wells except the cell control wells. Sera and virus were incubated together for $2 \mathrm{~h}$ at $37^{\circ} \mathrm{C}$. After incubation, $100 \mu \mathrm{l}$ of the sera and virus mixture was added to the plates seeded with FRhK-4 cells. After 3 days, the cell medium was decanted off and plates were washed once in $200 \mu \mathrm{l}$ PBS. The PBS was then decanted off and the cells were fixed with $100 \mu \mathrm{l}$ cold $80 \%$ acetone in PBS for $10 \mathrm{~min}$ at room temperature. The acetone was then decanted off and the plates were air dried for $20 \mathrm{~min}$ by inverting over the front air grill of a biosafety cabinet to ensure evaporation of the fixative. Plates were then washed five times in $1 \times$ PBS (Fisher) with $0.05 \%$ Tween 20 (Sigma) and incubated for $1 \mathrm{~h}$ in the dark with $100 \mu \mathrm{l}$ mouse anti-HAV VP3 primary antibody $(1 \mu \mathrm{g}$ $\mathrm{ml}^{-1}$; Accurate Chemical) in $5 \% \mathrm{FBS} / \mathrm{PBS}$. Plates were washed five times in $0.05 \%$ Tween 20/PBS and incubated for $1 \mathrm{~h}$ in the dark with $100 \mu \mathrm{l}$ horseradish peroxidase-conjugated goat anti-mouse IgG Fc secondary antibody (Bethyl) diluted 1:10000 in 5\% FBS/PBS. Plates were then washed a further five times in $0.05 \%$ Tween 20/PBS and developed with $100 \mu \mathrm{l}$ TMB substrate (BioFX Laboratories) for 12 min. TMB-Stop solution (100 $\mu$; BioFX Laboratories) was added to stop the reaction. The $A_{450}$ was then read on a microplate reader (EMax; Molecular Devices). Neutralization was defined as the ability of serum to neutralize HAV by $>50 \%$ compared with the virus control. The percentage neutralization was calculated by the following formula, using mean absorbance values from virus control (VC), cell control (CC) and serum sample wells: \% neutralization $=(\mathrm{VC}-$ absorbance obtained for a dilution of serum $) /$ $(\mathrm{VC}-\mathrm{CC}) \times 100$.

Statistical analysis. A $t$-test was applied for the statistical analysis of the data and was conducted with a Mann-Whitney test using Prism software.

\section{RESULTS AND DISCUSSION}

HAV grows exceptionally slowly in cell culture, and this has been problematic for the rapid detection of the virus by various assays (Bishop \& Anderson, 1997; Gosert et al., 2000; Pinto et al., 2007). Methods for quantification of this virus have been limited mainly to complex assays (Sanchez et al., 2006; Siegl et al., 1984; Yeh et al., 2008). Although anti-HAV antibodies can be detected by ELISA, this assay cannot exclusively measure neutralizing antibodies (Lemon et al., 1992; Shouval et al., 1993). The present study describes a novel application of an existing neutralization assay that relies principally on a cytopathic variant of HAV (HM175/18f), HAV-permissive FRhK-4 cells and a monoclonal antibody to the HAV VP3 structural protein. We first measured HAV infectivity by flow cytometry and subsequently by a microplate-based enzymic assay. As newly formed HAV virions tend to remain trapped within cells, permeabilization of the cells at the time of fixation and during their preparation for flow cytometry was necessary to maximize the reactivity of the anti-VP3 antibody with cell-associated virus. This method has been used previously for the detection and quantification of rabies neutralizing antibodies (Bordignon et al., 2002a, b). However, we were not able to differentiate between HAVinfected and uninfected FRhK-4 cells over 1-5 days (data not shown), regardless of the amount of virus or concentration of antibody used. Thereafter, the infectivity of FRhK-4 cells was measured by a microplate-based enzymic method, based on quantifying the amount of HAV VP3 antigen present in the infected cells. FRhK-4 cells were inoculated with different amounts of HM175/18f HAV and incubated for 3 days. At daily intervals, cells were fixed and HAV VP3 antigen was quantified by indirect ELISA of cellassociated viral VP3 antigen. At a viral concentration of $0.5 \times 10^{5}$ p.f.u. per well, viral antigen became detectable within $48 \mathrm{~h}$ after HAV inoculation, and after $72 \mathrm{~h}$ the signal: noise ratio between infected and uninfected cells was easily discernible and approached 3:1 (Fig. 1). Additional incubation time (days 4 and 5) increased the background and did not show any improvement in the assay (data not shown). These results indicated that HAV infection may be detected significantly sooner than in previously described assays. Based on these results, we examined the ability of sera from humans and monkeys vaccinated with the Havrix 1440 vaccine to neutralize HAV. Various conditions, such as virus titre, fixative, cell density and antibody concentration, were optimized. Fourfold dilutions of four human sera were set up in 96well plates and incubated with HM175/18f HAV. After a $2 \mathrm{~h}$ incubation at $37^{\circ} \mathrm{C}$, virus and serum mixtures were added to the pre-seeded cells and the plates were incubated at $37{ }^{\circ} \mathrm{C}$ for 3 days. Cells were fixed and stained with

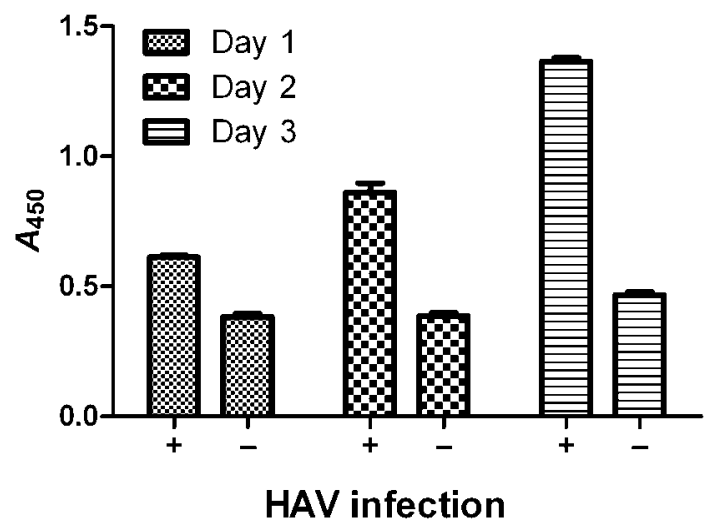

Fig. 1. Microplate-based enzymic method for measuring HAV in infected and uninfected FRhK-4 cells over 1-3 days. Infected and uninfected FRhK-4 cells were fixed and HAV VP3 antigen was quantified by direct ELISA. 
anti-HAV VP3 primary antibody and horseradish peroxidase-conjugated goat anti-mouse secondary antibody. After the addition of the chromogenic substrate, the colorimetric reaction was stopped and the $A_{450}$ was read on a microplate reader. All serum dilutions tested (up to $1: 100000)$ were able to neutralize the virus by $>50 \%$ compared with the virus control (Fig. 2). Control sera (non-vaccinated) were not able to neutralize HAV beyond $10-15 \%$, even at a $1: 40$ dilution. The fundamental difference between this method and previously described methods is that, unlike this method, previous methods require a longer time and higher levels of HAV replication. In addition, most methods require cell destruction to release cell-associated virus, whereas in this assay a $10 \mathrm{~min}$ fixation by acetone appeared to suffice. Additionally, we evaluated a different fixative for use in our mircroplatebased assay, namely BD FixPerm reagent (BD Biosciences). However, this reagent was shown to be inappropriate for use in a microplate assay due to the excessive foaming produced in the plate wells during the washing and developing steps. We attributed this to the presence of saponins in the BD Perm/Wash buffer.

In summary, we have shown that it is possible to detect HAV infection in microplate-based cultures of FRhK-4 cells after only 3 days, instead of the typical 8-21 days required in other assays. Additionally, we have demonstrated that it is also possible to detect the presence of

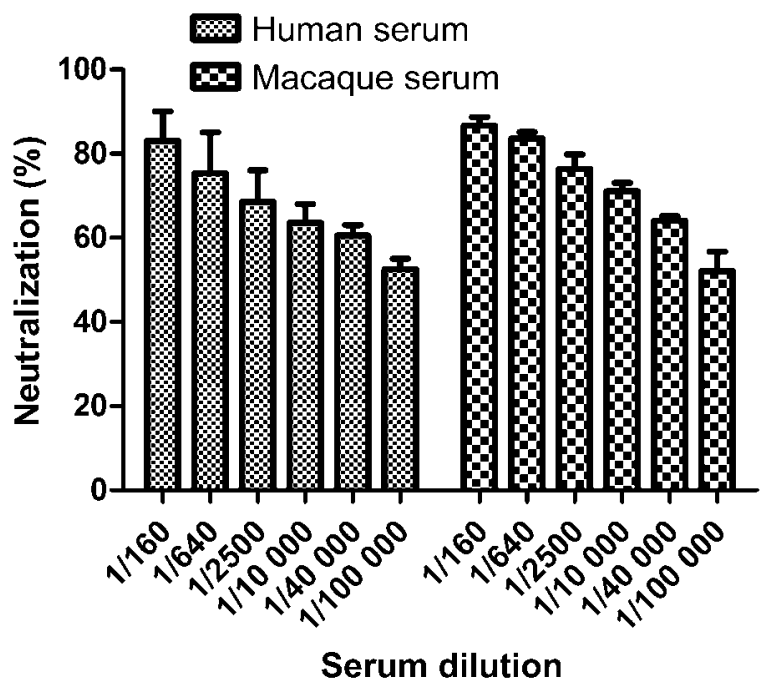

Fig. 2. Neutralization of HAV in vaccinated human and rhesus macaque sera. Serum samples from humans and monkeys $(n=3)$ immunized with the Havrix 1440 vaccine were collected 2 weeks after the last vaccination. Diluted serum samples were incubated with $\mathrm{HM} 175 / 18 \mathrm{f}$ virus for $2 \mathrm{~h}$ and then added to pre-seeded FRhK-4 cells. The plates were developed after 3 days as described in Methods, and the percentage neutralization was calculated. Data are shown as the group mean \pm SEM. Sera from non-vaccinated animals did not neutralize virus beyond $10-15 \%$, even at a $1: 40$ dilution. functional HAV neutralizing antibodies within this brief time period. The implications of these findings are important for the rapid measurement of the immunogenicity of HAV vaccines, and for virological studies and diagnostic purposes.

\section{ACKNOWLEDGEMENTS}

We acknowledge Dr Syed Sattar in the Department of Microbiology and Immunology at the University of Ottawa, Canada, for providing FRhK-4 cells and the HM175/18f HAV isolate. We would like to thank Mrs Jasminka Bozic and Dr Marko Kryworuchko for technical assistance

\section{REFERENCES}

Beales, L. P., Wood, D. J., Minor, P. D. \& Saldanha, J. A. (1996). A novel cytopathic microtitre plate assay for hepatitis A virus and antihepatitis A neutralizing antibodies. J Virol Methods 59, 147-154.

Bishop, N. E. \& Anderson, D. A. (1997). Early interactions of hepatitis A virus with cultured cells: viral elution and the effect of $\mathrm{pH}$ and calcium ions. Arch Virol 142, 2161-2178.

Bordignon, J., Comin, F., Ferreira, S. C., Caporale, G. M., Lima Filho, J. H. \& Zanetti, C. R. (2002a). Calculating rabies virus neutralizing antibodies titres by flow cytometry. Rev Inst Med Trop Sao Paulo 44, 151-154.

Bordignon, J., Pires Ferreira, S. C., Medeiros Caporale, G. M., Carrieri, M. L., Kotait, I., Lima, H. C. \& Zanetti, C. R. (2002b). Flow cytometry assay for intracellular rabies virus detection. J Virol Methods 105, 181-186.

Brack, K., Frings, W., Dotzauer, A. \& Vallbracht, A. (1998). A cytopathogenic, apoptosis-inducing variant of hepatitis A virus. J Virol 72, 3370-3376.

Brown, F. (1989). The classification and nomenclature of viruses: summary of results of meetings of the International Committee on Taxonomy of Viruses in Edmonton, Canada 1987. Intervirology 30, 181-186.

Cao, J., Meng, S., Li, C., Ji, Y., Meng, Q., Zhang, Q., Liu, F., Li, J., Bi, S. \& other authors (2008). Efficient neutralizing activity of cocktailed recombinant human antibodies against hepatitis A virus infection in vitro and in vivo. J Med Virol 80, 1171-1180.

Chen, H. \& Cantrell, C. R. (2006). Prevalence and factors associated with self-reported vaccination rates among US adults at high risk of vaccine-preventable hepatitis. Curr Med Res Opin 22, 2489-2496.

Emerson, S. U., Huang, Y. K. \& Purcell, R. H. (1993). 2B and 2C mutations are essential but mutations throughout the genome of HAV contribute to adaptation to cell culture. Virology 194, 475-480.

Endo, K., Takahashi, M., Masuko, K., Inoue, K., Akahane, Y. \& Okamoto, H. (2007). Full-length sequences of subgenotype IIIA and IIIB hepatitis A virus isolates: characterization of genotype III HAV genomes. Virus Res 126, 116-127.

Gauss-Muller, V., Lottspeich, F. \& Deinhardt, F. (1986). Characterization of hepatitis A virus structural proteins. Virology 155, 732-736.

Gosert, R., Egger, D. \& Bienz, K. (2000). A cytopathic and a cell culture adapted hepatitis A virus strain differ in cell killing but not in intracellular membrane rearrangements. Virology 266, 157-169.

Jelic, O., Fornet-Sapcevski, J., Kovacevic, L., Pandak, N. \& Jelic, D. (1990). Recurrences of viral hepatitis A. Acta Med Iugosl 44, 565-576.

Kim, S. J., Jang, M. H., Stapleton, J. T., Yoon, S. O., Kim, K. S., Jeon, E. S. \& Hong, H. J. (2004). Neutralizing human monoclonal 
antibodies to hepatitis A virus recovered by phage display. Virology 318, 598-607.

Konduru, K., Virata-Theimer, M. L., Yu, M. Y. \& Kaplan, G. G. (2008). A simple and rapid hepatitis A virus (HAV) titration assay based on antibiotic resistance of infected cells: evaluation of the HAV neutralization potency of human immune globulin preparations. Virol J 5, 155.

Lemon, S. M., Murphy, P. C., Shields, P. A., Ping, L. H., Feinstone, S. M., Cromeans, T. \& Jansen, R. W. (1991). Antigenic and genetic variation in cytopathic hepatitis A virus variants arising during persistent infection: evidence for genetic recombination. J Virol 65, 2056-2065.

Lemon, S. M., Jansen, R. W. \& Brown, E. A. (1992). Genetic, antigenic and biological differences between strains of hepatitis A virus. Vaccine 10, S40-S44.

Nainan, O. V., Xia, G., Vaughan, G. \& Margolis, H. S. (2006). Diagnosis of hepatitis A virus infection: a molecular approach. Clin Microbiol Rev 19, 63-79.

Pinto, R. M., Aragones, L., Costafreda, M. I., Ribes, E. \& Bosch, A. (2007). Codon usage and replicative strategies of hepatitis A virus. Virus Res 127, 158-163.
Sanchez, G., Populaire, S., Butot, S., Putallaz, T. \& Joosten, H. (2006). Detection and differentiation of human hepatitis A strains by commercial quantitative real-time RT-PCR tests. J Virol Methods 132, 160-165.

Shouval, D., Ashur, Y., Adler, R., Lewis, J. A., Armstrong, M. E., Davide, J. P., McGuire, B., Kuter, B., Brown, L. \& other authors (1993). Single and booster dose responses to an inactivated hepatitis A virus vaccine: comparison with immune serum globulin prophylaxis. Vaccine 11, S9-S14.

Siegl, G., Dechastonay, J. \& Kronauer, G. (1984). Propagation and assay of hepatitis A virus in vitro. J Virol Methods 9, 53-67.

Stapleton, J. T., Raina, V., Winokur, P. L., Walters, K., Klinzman, D., Rosen, E. \& McLinden, J. H. (1993). Antigenic and immunogenic properties of recombinant hepatitis A virus $14 \mathrm{~S}$ and $70 \mathrm{~S}$ subviral particles. J Virol 67, 1080-1085.

Yeh, H. Y., Hwang, Y. C., Yates, M. V., Mulchandani, A. \& Chen, W. (2008). Detection of hepatitis A virus by using a combined cell culturemolecular beacon assay. Appl Environ Microbiol 74, 2239-2243.

Zahn, J., Vallbracht, A. \& Flehmig, B. (1984). Hepatitis A-virus in cell culture. V. Neutralizing antibodies against hepatitis A-virus. Med Microbiol Immunol 173, 9-17. 